\title{
Thyroid-related ophthalmopathy development in concurrence with growth hormone administration
}

Shimpei Iwata ${ }^{1}$, Kenji Tsumura ${ }^{1,2}$, Kenji Ashida ${ }^{1 *}$, Ichiro Tokubuchi ${ }^{1,3}$, Mutsuyuki Demiya ${ }^{1,3}$, Miyuki Kitamura ${ }^{1,4}$, Hiroyuki Ohshima ${ }^{5}$, Mamiko Yano ${ }^{1}$, Ayako Nagayama', Junichi Yasuda', Munehisa Tsuruta', Seiichi Motomura', Shigeo Yoshida ${ }^{5}$ and Masatoshi Nomura ${ }^{1}$

\begin{abstract}
Background: Thyroid stimulating hormone (TSH) receptor and local infiltrate lymphocytes have been considered as major pathological factors for developing thyroid-related ophthalmopathy. Overexpression of insulin-like growth factor-I (IGF-I) receptor has emerged as a promising therapeutic target for refractory patients. However, the relationship between activation of growth hormone (GH)/IGF-I receptor signaling and development or exacerbation of thyroid ophthalmopathy has not been elucidated. Herein we describe a case that provides further clarification into the association between thyroid-related ophthalmopathy and GH/IGF-I receptor signaling.

Case presentation: A 62-year-old Japanese female diagnosed with thyroid-related ophthalmopathy was admitted to Kurume University Hospital. She had received daily administration of GH subcutaneously for severe GH deficiency; however, serum IGF-I levels were greater than +2 standard deviation based on her age and sex. She exhibited mild thyrotoxicosis and elevation in levels of TSH-stimulating antibody. Discontinuation of GH administration attenuated the clinical activity scores of her thyroid-related ophthalmopathy. Additionally, concomitant use of glucocorticoid and radiation therapies resulted in further improvement of thyroid-related ophthalmopathy. The glucocorticoid administration was reduced sequentially, followed by successful termination. Thereafter, the patient did not undergo recurrence of thyroid-related ophthalmopathy and maintained serum IGF-I levels within normal physiological levels.

Conclusions: We describe here a case in which development of thyroid-related ophthalmopathy occurred upon initiation of GH administration. GH/IGF-I signaling was highlighted as a risk factor of developing thyroid-related ophthalmopathy. Additionally, aberrant TSH receptor expression was suggested to be a primary pathophysiological mechanism within the development of thyroid-related ophthalmopathy. Physicians should be aware of the risks incurred via GH administration, especially for patients of advanced age, for induction of thyroid-related ophthalmopathy.
\end{abstract}

Keywords: Thyroid-related ophthalmopathy, Growth hormone, Insulin-like growth factor-l, Graves' disease

\footnotetext{
* Correspondence: ashida@med.kurume-u.ac.jp

'Division of Endocrinology and Metabolism, Department of Internal

Medicine, Kurume University School of Medicine, 67 Asahi-machi, Kurume,

Fukuoka 830-0011, Japan

Full list of author information is available at the end of the article
}

(c) The Author(s). 2021 Open Access This article is licensed under a Creative Commons Attribution 4.0 International License, which permits use, sharing, adaptation, distribution and reproduction in any medium or format, as long as you give appropriate credit to the original author(s) and the source, provide a link to the Creative Commons licence, and indicate if changes were made. The images or other third party material in this article are included in the article's Creative Commons licence, unless indicated otherwise in a credit line to the material. If material is not included in the article's Creative Commons licence and your intended use is not permitted by statutory regulation or exceeds the permitted use, you will need to obtain permission directly from the copyright holder. To view a copy of this licence, visit http://creativecommons.org/licenses/by/4.0/. The Creative Commons Public Domain Dedication waiver (http://creativecommons.org/publicdomain/zero/1.0/) applies to the data made available in this article, unless otherwise stated in a credit line to the data. 


\section{Background}

Thyroid-related ophthalmopathy is an autoimmune disease that reduces quality of life due to visual disturbance related to orbitopathy, and is often refractory to various therapies [1]. The thyroid stimulating hormone (TSH) receptor is considered to be a major player in the development of thyroid-related ophthalmopathy [2, 3]. Local infiltrating lymphocytes have also been implicated in the pathogenesis of this disease [3]. Glucocorticoid therapy, either orally, intravenously as steroid pulse therapy, or via orbital local injection, as well as radiation therapy are the primary therapeutic approaches employed to attenuate inflammation and prevent fibrosis in post-orbital tissue $[2,4]$. However, these traditional therapies used in accordance with current guidelines sometimes fail to ameliorate ophthalmopathy, leading to persistent and/or recurrent disease.

The insulin-like growth factor-I (IGF-I) receptor in orbital organs has recently been implicated as an emerging therapeutic target for thyroid ophthalmopathy [5]. A clinical trial using an IGF-I receptor inhibitor for treatment of thyroid-related ophthalmopathy is ongoing [6]. Additionally, immune activation by the growth hormone (GH)/IGF-I has been disclosed in previous literatures [7]. In this context, involvement of GH/IGF-I signal in thyroid-related ophthalmopathy has been further elucidated. However, whether GH administration entails a risk for development or exacerbation of thyroid ophthalmopathy remains unclear.

The present case report describes a patient exhibiting thyroid-related ophthalmopathy that developed after the initiation of $\mathrm{GH}$ subcutaneous administration for treatment of adult GH deficiency (GHD), and improved concomitant with discontinuation of these injections [8]. The patient tested negative for TSH receptor antibody (TRAb) and mild elevation in thyroid stimulating antibody (TSAb) [9], which suggested a potential role of the GH/IGF-I system in the pathogenesis of thyroid-related ophthalmopathy (Supplemental Figure 1). Physicians should be aware of the risk for thyroid-related ophthalmopathy as a potential adverse event of $\mathrm{GH}$ administration.

\section{Case presentation}

A 62-year-old Japanese female patient was admitted to the endocrinology center of Kurume University Hospital complaining of recent orbital pain, especially during eye movement and bilateral eyelid swellings. One year prior to her visit, she was diagnosed with severe adult GHD and secondary hypothyroidism due to low levels of both TSH and free thyroxine (T4) $[10,11]$, and insufficient elevation in GH and TSH levels following intravenous administration of $100 \mu \mathrm{g}$ of GH-releasing peptide-2 (GHRP-2) or $200 \mathrm{mg}$ of thyrotropin releasing hormone

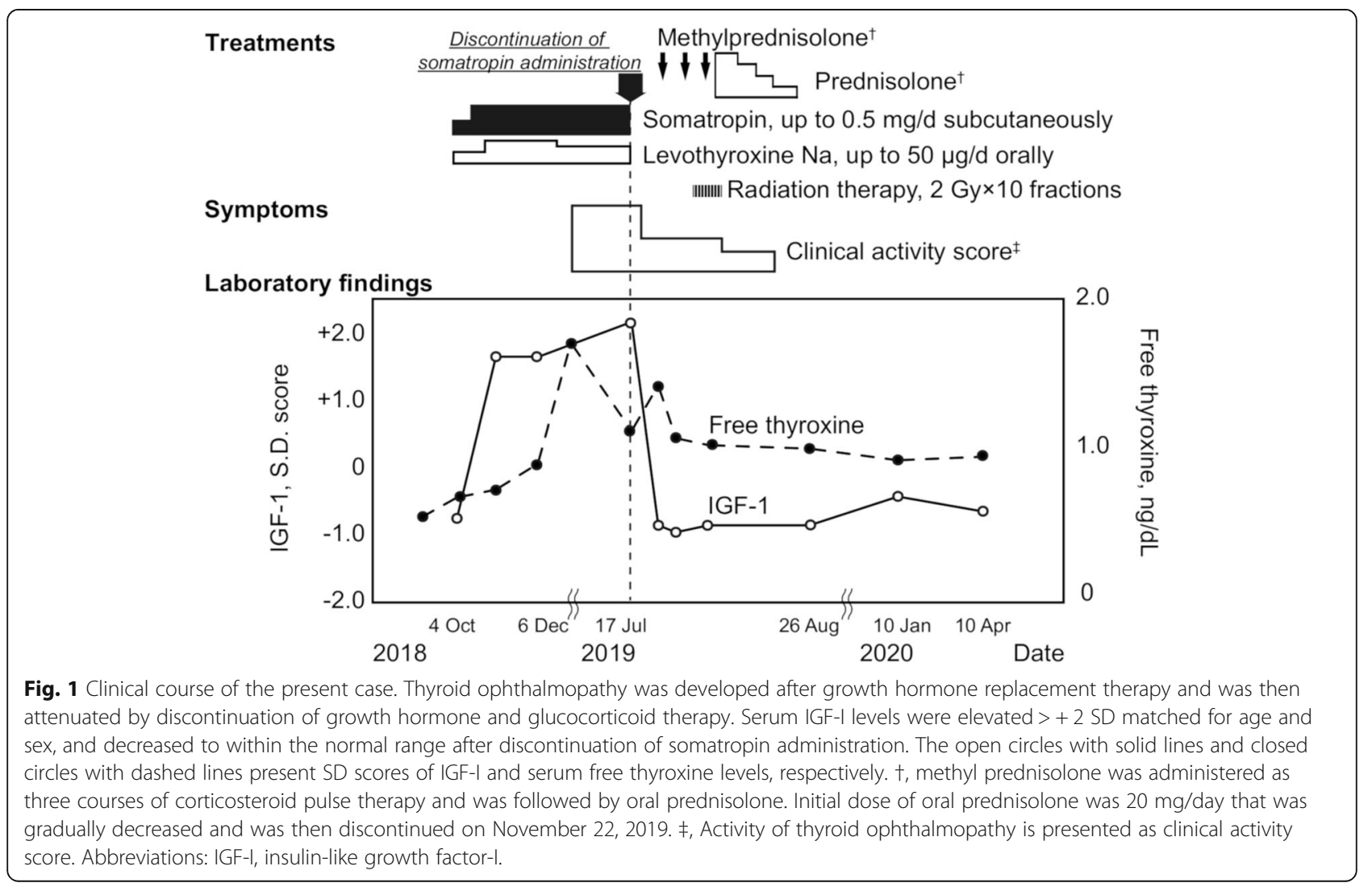


(TRH) (Supplemental Table 1). Thus, the patient was administered $0.5 \mathrm{mg} /$ day of subcutaneous somatropin, recombinant $\mathrm{GH}$, injection and $50 \mu \mathrm{g} /$ day of oral levothyroxine. The clinical course is shown in Fig. 1.

Upon physical examinations, bilateral swelling of the eyelids was observed. Magnetic resonance imaging (MRI) revealed swelling of bilateral lachrymal gland and right upper eyelid edema (Fig. 2), which suggested thyroid-related ophthalmopathy; however, hypertrophy of the extraocular muscles was not detected. An MRI time course was displayed sequentially at diagnosis, at 13 days after GH discontinuation, and after ophthalmopathy treatment (Fig. 2). The subject was diagnosed with thyrotoxicosis based on clinical symptoms, including sweating and palpitation, as well as laboratory findings upon admission (Table 1). We discontinued levothyroxine administration when the patient was diagnosed with Graves' disease based on clinical findings, including positive detection of TSAb [9], increased blood flow in diffuse goiter shown by ultrasonography, and preserved diffuse ${ }^{123} \mathrm{I}$ uptake by $4.7 \%$ in the thyroid gland under thyrotoxicosis (Fig. 3). In addition, neither free thyronine nor free T4 levels decreased, and TSH remained below the detection level even following levothyroxine discontinuation. The clinical activity score (CAS) for thyroidrelated ophthalmopathy was 3: positive for orbital pain, pain during eye movement, and lachrymal gland and eyelid swelling.

Somatropin, administered at $0.5 \mathrm{mg} /$ day subcutaneously, was also discontinued since serum IGF-I levels were elevated to $205 \mathrm{ng} / \mathrm{mL}$ (reference range for \pm 2 standard deviation [SD]: 68-196) [12]. Orbital oppression and left lachrymal gland swelling were attenuated after somatropin discontinuation (Fig. 2). Three sequential courses of corticosteroid pulse therapy (each course involved intravenous drip infusion of $0.5 \mathrm{~g} /$ day methyl

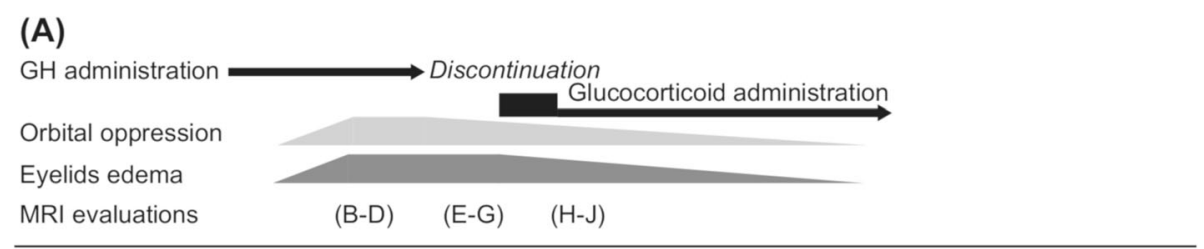

(B) (E) $\quad(\mathrm{H})$
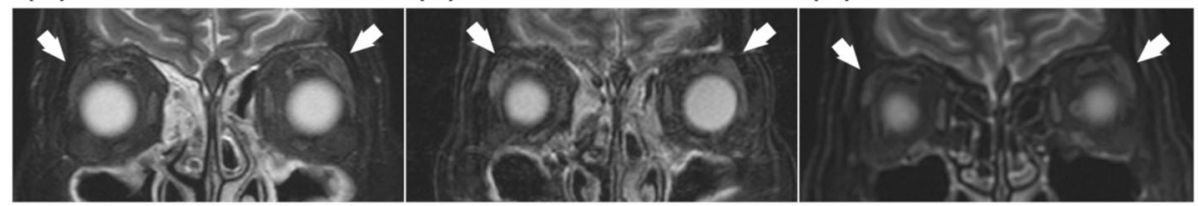

(C)

(F)

(l)
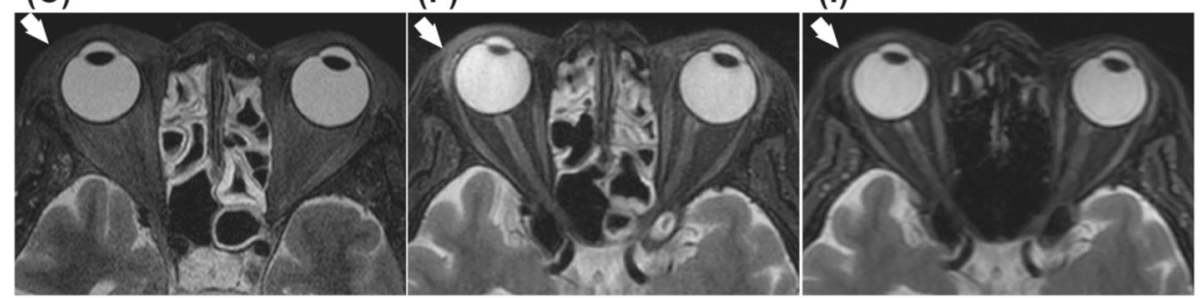

(D)

(G)

(J)

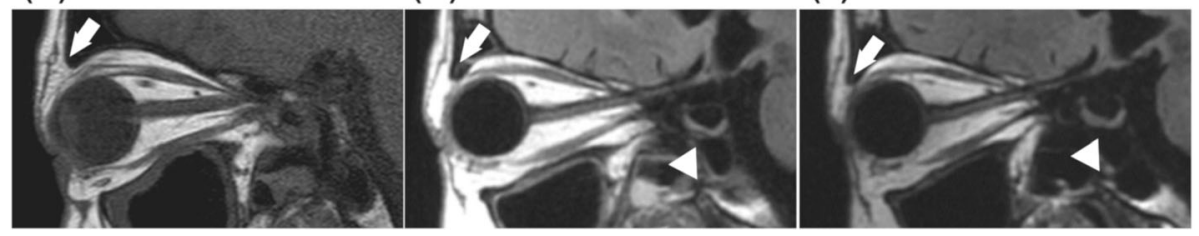

Fig. 2 Sequential change of thyroid-related ophthalmopathy demonstrated by magnetic resonance imaging. The clinical course of growth hormone and glucocorticoid therapy, symptoms of Graves' ophthalmopathy, and points of MRI evaluations are displayed (A). The bilateral lachrymal glands swelling, especially in left side (B), and right eyelid swelling (C, D) indicating thyroid-related ophthalmopathy after growth hormone replacement are shown. Minimal attenuation of swellings in lachrymal glands is shown after growth hormone discontinuation (E), while edematous change in right eyelid persisted $(\mathbf{F}, \mathbf{G})$. Glucocorticoid therapies improve further bilateral lachrymal glans and right eyelid edema $(\mathbf{H}, \mathbf{I}$, J). (B, E, H): frontal section of T2 weighted image. (C, F, I): horizontal section of T2 weighted image (C: short T1 inversion recovery; $F$ and I: iterative decomposition of water and fat with echo asymmetry and least squares estimation). (D, G, J): sagittal section image (D: T1 weighted image; $\mathbf{G}$ and J: fluid-attenuated inversion recovery). Arrows indicate bilateral lachrymal gland (B, E, H) and right eyelids (C, D, F, G, I, J). Arrowheads $(\mathbf{G}, \mathbf{J})$ indicate pituitary gland exhibiting a mild compression form 
Table. 1 Laboratory findings at admission

\begin{tabular}{lll}
\hline Parameters & Value & Reference range \\
\hline Thyroid gland & & \\
TSH, $\mu \mathrm{IU} / \mathrm{mL}$ & $<0.005$ & $0.5-5.0$ \\
Free $\mathrm{T} 3, \mathrm{pg} / \mathrm{dL}$ & 4.2 & $2.3-4.0$ \\
Free $\mathrm{T} 4, \mathrm{ng} / \mathrm{mL}$ & 1.07 & $0.93-1.70$ \\
Anti-Tg Ab, IU/L & 94 & $<28$ \\
Anti-TPO Ab, IU/L & 348 & $<16$ \\
TSAb, \% & 152 & $<120$ \\
TRAb, IU/L & 1.9 & $<2.0$ \\
Growth hormone & & \\
Growth hormone, ng/mL & 1.49 & $0.13-9.88$ \\
IGF-I, $\mathrm{ng} / \mathrm{mL}$ (SD score $\left.{ }^{\mathrm{a}}\right)$ & $205(+2.2 \mathrm{SD})$ & $68-196$ \\
Other endocrinology & & \\
ACTH, pg/mL & 63.7 & $7.2-63.3$ \\
cortisol, $\mu \mathrm{mg} / \mathrm{dL}$ & 10.1 & $6.24-18.0$ \\
LH, mIU/mL & 29.7 & $5.72-64.31$ \\
FSH, $\mathrm{mlU} / \mathrm{mL}$ & 44.8 & $<157.79$ \\
Estradiol, pg/mL & $<5.0$ & $<47.0$ \\
\hline
\end{tabular}

${ }^{a}$ SD score of IGF-I was calculated in accordance with LMS method [12] Abbreviations: $A C T H$ adrenocorticotropic hormone; anti-Tg Ab antithyroglobulin antibody; anti-TPO Ab anti-thyroid peroxidase antibody; IGF$I$ insulin-like growth factor-l; $L H$ luteinizing hormone; $F S H$ follicle-stimulating hormone; SD standard deviation; TRAb TSH receptor antibody; TSAb thyroid stimulating antibody. prednisolone [PSL] for 3 days followed by $20 \mathrm{mg} /$ day oral PSL for 4 sequential days) and fractional radiation therapy (20 total gray at 2 Gy/day for 10 days) were performed. CAS was improved to zero points, and orbital MRI demonstrated improvement in lachrymal glands swellings and right eyelid edema (Fig. 2). Furthermore, we were able to terminate oral prednisolone administration without recurrence of ophthalmopathy for an additional year (Fig. 1).

\section{Discussion and conclusions}

To the best of our knowledge, this is the first described case in which thyroid-related ophthalmopathy could be induced by GH administration. This study highlights GH/IGF-I receptor signaling as a key risk factor for thyroid-related ophthalmopathy, although aberrant TSH receptor expression is known to be a major involved pathophysiological mechanism. Physicians should be aware of the risk of $\mathrm{GH}$ administration for the patients with upper middle or advanced age in induction of thyroid-related ophthalmopathy.

This study demonstrated compelling evidence that GH administration can induce thyroid-related ophthalmopathy. The development and activity of ophthalmopathy are positively correlated with the levels of TSH receptor antibody [13, 14]. In this context, mild elevation of TSAb may indicate that the GH administration enhanced GH/IGF-I signaling highly contributed to thyroid-related ophthalmopathy development in this case. Subcutaneous administration of GH for one month

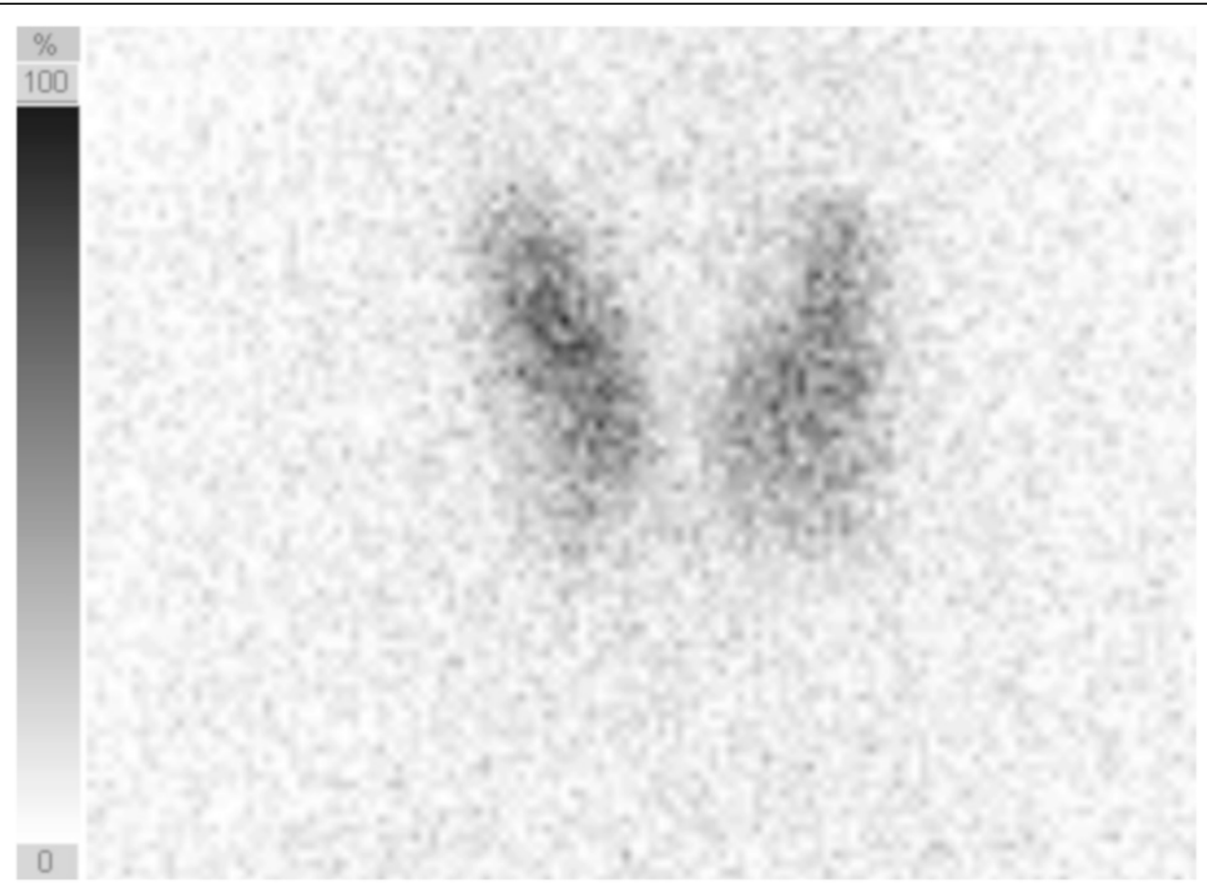

Fig. 3 Thyroid gland uptake of ${ }^{123}$-scintigraphy. Diffuse uptake of ${ }^{123} \mathrm{l}$ by $4.7 \%$ is demonstrated under the thyrotoxicosis condition after $3 \mathrm{~h}$ 
led to occurrence of bilateral swelling of the lachrymal glands and the eyelids. Discontinuation of GH administration alone attenuated this orbital oppression, and glucocorticoid combined with radiation therapies provided further improvement (Figs. 1 and 2). Thus, excessive activity of GH/IGF-I is highlighted as a risk factor for developing thyroid ophthalmopathy. Physicians should be vigilant about the risk that thyroid-related ophthalmopathy may be induced by GH initiation, and they should adjust the GH dose to regulate IGF-I levels within normal range [12].

This study suggests that GH administration can be a key factor within thyroid-related ophthalmopathy development. The pathological cooperative signals of the TSH and IGF-I receptors in bone marrow-derived fibroblasts-which lead to the production of inflammatory molecules and hyaluronan, as well as adipogenesis in orbital organs-have been previously described [15-18] (Supplemental Figure 1). Given the IGF-I receptor antibody, teprotumumab, improved thyroid ophthalmopathy [19], it is conceivable that the activation of GH/IGF-I signaling is involved in ophthalmopathy development. The current study also suggests that Graves' disease and aging may contribute to the overexpression of IGF-I receptor and aberrant expression of TSH receptor. Additionally, estrogens are known to antagonize the production of IGF-I in GHD patients under GH replacement therapy [20]. GH/IGF-I signaling could be modulated in post-menopausal women, as in the present case, compared to women of fertile age. Therefore, modulating factors of GH/IGF-I signaling, including menopause, should also be considered.

GH/IGF-I hyperactivity may induce or aggravate ophthalmopathy, especially in patients with a background of Graves' disease. GH administration can exacerbate inflammation in orbital tissues via activation in autoimmunity (Supplemental Figure 1) [7]. However, thyroid-related ophthalmopathy complicated with acromegaly has not been previously reported. In children and adolescents exhibiting elevated GH/IGF-I activities, the pathophysiological mechanisms of thyroid ophthalmopathy are considered to be similar to those in adult patients [21]. However, thyroid ophthalmopathy is rare in children and adolescents [13]. Scarce evidence of thyroid-related ophthalmopathy in young people indicates that abnormal expression of the TSH receptor may be due to primary etiology, while GH/IGF-I signaling can enhance ophthalmopathy (Supplemental Figure 1). The expression levels of the IGF-I receptor within orbital tissues in patients with thyroid-related ophthalmopathy may alter with aging. Age-related decreases in local IGF-I binding protein levels may be another plausible reason for this phenomenon [22]. We could not confirm aberrant TSH receptor expression nor IGF-I receptor overexpression within the orbital tissues in our patient. To corroborate our conclusions, further case or clinical studies are warranted.

In conclusion, we describe a patient with thyroidrelated ophthalmopathy that was induced by GH administration. GH/IGF-I signaling was highlighted as a risk factor of developing thyroid-related ophthalmopathy. Physicians should be aware of the risk of GH administration in patients at an advanced age who are at a risk of developing thyroid-related ophthalmopathy.

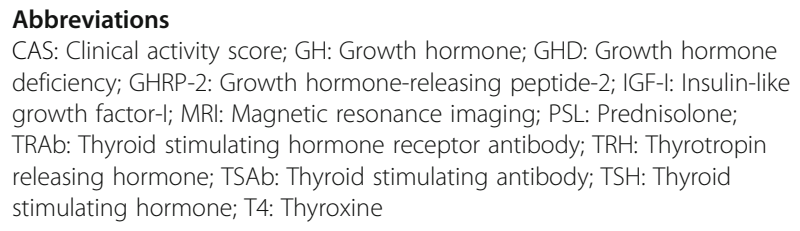
deficiency; GHRP-2: Growth hormone-releasing peptide-2; IGF-I: Insulin-like growth factor-l; MRI: Magnetic resonance imaging; PSL: Prednisolone; TRAb: Thyroid stimulating hormone receptor antibody; TRH: Thyrotropin releasing hormone; TSAb: Thyroid stimulating antibody; TSH: Thyroid stimulating hormone; T4: Thyroxine

\section{Supplementary Information}

The online version contains supplementary material available at https://doi. org/10.1186/s12902-021-00834-2.

Additional file 1: Supplemental Table S1. Pituitary gland hormone responses to pituitary stimulation tests.

Additional file 2: Supplemental Figure S1. Hypothesis of pathological mechanisms in this case.

\section{Acknowledgements \\ The authors would like to thank Enago (www.enago.jp) for the English language review.}

\section{Authors' contributions}

$\mathrm{SI}$ and $\mathrm{KA}$ designed the study and drafted the first manuscript. SI, KT, and KA collected the data. SI, KT, KA, IT, MD, MY, HO, and MN interpreted the data. $S I, K T, K A, I T, M D, M K, H O, M Y, A N, J Y, M T, S M, S Y$, and MN provided input in the preparation of the manuscript. SI, KA, and $M N$ revised the manuscript. All authors have read and approved the final version of manuscript.

\section{Funding}

This research did not receive any specific grant from any funding agency in the public, commercial, or not-for-profit sectors.

\section{Availability of data and materials}

All data generated or analyzed during this study are included in this published article and its supplementary information files.

\section{Declarations}

Ethics approval and consent to participate

All procedures performed in this study were in accordance with the ethical standards of the Institutional Review Board of Kurume University Hospital and with the principles of the Declaration of Helsinki 2013. Written informed consent to participate in this study was obtained from the patients. The Institutional Review Board of Kurume University Hospital (2020-045) approved this report.

\section{Consent for publication}

Written informed consent for publication of the clinical details was obtained from the patients.

Competing interests

The authors have no conflicts of interest to declare. 


\section{Author details}

${ }^{1}$ Division of Endocrinology and Metabolism, Department of Internal Medicine, Kurume University School of Medicine, 67 Asahi-machi, Kurume, Fukuoka 830-0011, Japan. ${ }^{2}$ Clinical training center, Kurume University Hospital, Kurume, Fukuoka, Japan. ${ }^{3}$ Division of Endocrinology and Metabolism, Omuta City Hospital, Omuta, Fukuoka, Japan. ${ }^{4}$ Department of Pediatrics and Child Health, Kurume University School of Medicine, Kurume, Fukuoka, Japan. ${ }^{5}$ Department of Ophthalmology, Kurume University School of Medicine, Kurume, Fukuoka, Japan.

Received: 21 October 2020 Accepted: 4 August 2021

Published online: 19 August 2021

\section{References}

1. Bahn RS. Graves' ophthalmopathy. N Engl J Med. 2010;362:726-38.

2. Bartalena L, Baldeschi L, Boboridis K, Eckstein A, Kahaly GJ, Marcocci C, et al. The 2016 European Thyroid association/European group on graves' orbitopathy guidelines for the management of Graves' orbitopathy. Eur Thyroid J. 2016;5:9-26.

3. Otto EA, Ochs C, Hansen C, Wall JR, Kahaly GJ. Orbital tissue-derived t lymphocytes from patients with Graves' ophthalmopathy recognize autologous orbital antigens. J Clin Endocrinol Metab. 1996;81:3045-50.

4. Ueda-Sakane Y, Kanamoto N, Fushimi Y, Tanaka-Mizuno S, Yasuno S, Miura $\mathrm{M}$, et al. Overall safety and efficacy of high-dose and low-dose intravenous glucocorticoid therapy in patients with moderate-to-severe active Graves' ophthalmopathy. Endocr J. 2016;63:703-14.

5. Fröhlich E, Wahl R. Thyroid autoimmunity: role of anti-thyroid antibodies in thyroid and extra-thyroidal diseases. Front Immunol. 2017;8:521.

6. Douglas RS, Kahaly GJ, Patel A, Sile S, Thompson EHZ, Perdok R, et al. Teprotumumab for the treatment of active thyroid eye disease. N Engl $J$ Med. 2020;382:341-52

7. Bodart G, Farhat K, Charlet-Renard C, Salvatori R, Geenen V, Martens H. The somatotrope growth hormone-releasing hormone/growth hormone/insulinlike growth factor-1 axis in immunoregulation and immunosenescence. Front Horm Res. 2017:48:147-59.

8. Díez JJ, Sangiao-Alvarellos S, Cordido F. Treatment with growth hormone for adults with growth hormone deficiency syndrome: benefits and risks. Int J Mol Sci. 2018;19:893.

9. Kamijo K, Murayama H, Uzu T, Togashi K, Olivo PD, Kahaly GJ. Similar clinical performance of a novel chimeric thyroid-stimulating hormone receptor bioassay and an automated thyroid-stimulating hormone receptor binding assay in Graves' disease. Thyroid. 2011;21:1295-9.

10. Fleseriu M, Hashim IA, Karavitaki N, Melmed S, Murad MH, Salvatori R, et al. Hormonal replacement in hypopituitarism in adults: an endocrine society clinical practice guideline. J Clin Endocrinol Metab. 2016;101:3888-921.

11. Kasagi K, Shimatsu A, Miyamoto S, Misaki T, Sakahara H, Konishi J. Goiter associated with acromegaly: sonographic and scintigraphic findings of the thyroid gland. Thyroid. 1999;9:791-6.

12. Isojima T, Shimatsu A, Yokoya S, Chihara K, Tanaka T, Hizuka N, et al. Standardized centile curves and reference intervals of Serum Insulin-Like Growth factor-I (IGF-I) levels in a normal Japanese population using the LMS method. Endocr J. 2012;59:771-80.

13. Hiromatsu Y, Eguchi H, Tani J, Kasaoka M, Teshima Y. Graves' ophthalmopathy: epidemiology and natural history. Intern Med. 2014;53 $353-60$

14. Lytton SD, Ponto KA, Kanitz M, Matheis N, Kohn LD, Kahaly GJ. A novel thyroid stimulating immunoglobulin bioassay is a functional indicator of activity and severity of Graves' orbitopathy. J Clin Endocrinol Metab. 2010; 95:2123-31.

15. Smith TJ, Janssen JAMJL. Insulin-like Growth Factor-I receptor and thyroidassociated ophthalmopathy. Endocr Rev. 2019;40:236-67.

16. Tsui S, Naik V, Hoa N, Hwang CJ, Afifiyan NF, Sinha Hikim A, et al. Evidence for an association between thyroid-stimulating hormone and insulin-like growth factor 1 receptors: a tale of two antigens implicated in Graves' disease. J Immunol. 2008;181:4397-405.

17. Mohyi M, Smith TJ. IGF1 receptor and thyroid-associated ophthalmopathy. J Mol Endocrinol. 2018;61:T29-43.

18. Krieger CC, Morgan SJ, Neumann S, Gershengorn MC. Thyroid Stimulating Hormone (TSH)/Insulin-like Growth Factor 1 (IGF1) receptor cross-talk in human cells. Curr Opin Endocr Metab Res. 2018;2:29-33.
19. Smith TJ, Kahaly GJ, Ezra DG, Fleming JC, Dailey RA, Tang RA, et al. Teprotumumab for thyroid-associated ophthalmopathy. N Engl J Med. 2017; 376:1748-61.

20. Duarte FH, Jallad RS, Bronstein MD. Clomiphene citrate for treatment of acromegaly not controlled by conventional therapies. J Clin Endocrinol Metab. 2015;100:1863-9.

21. Szczapa-Jagustyn J, Gotz-Więckowska A, Kocięcki J. An update on thyroidassociated ophthalmopathy in children and adolescents. J Pediatr Endocrinol Metab. 2016;29:1115-22.

22. Oliver WT, Rosenberger J, Lopez R, Gomez A, Cummings KK, Fiorotto ML. The local expression and abundance of Insulin-Like Growth Factor (IGF) binding proteins in skeletal muscle are regulated by age and gender but not local IGF-I in vivo. Endocrinology. 2005;146:5455-62.

\section{Publisher's Note}

Springer Nature remains neutral with regard to jurisdictional claims in published maps and institutional affiliations.
Ready to submit your research? Choose BMC and benefit from:

- fast, convenient online submission

- thorough peer review by experienced researchers in your field

- rapid publication on acceptance

- support for research data, including large and complex data types

- gold Open Access which fosters wider collaboration and increased citations

- maximum visibility for your research: over $100 \mathrm{M}$ website views per year

At BMC, research is always in progress.

Learn more biomedcentral.com/submissions 